\title{
Photoenhanced wet oxidation of gallium nitride
}

\author{
L.-H. Peng, ${ }^{\text {a) }}$ C.-H. Liao, and Y.-C. Hsu \\ Department of Electrical Engineering and Institute of Electro-optical Engineering, National Taiwan \\ University, Taipei, Taiwan, Republic of China \\ C.-S. Jong, C.-N. Huang, ${ }^{\text {b) }}$ J.-K. Ho, C.-C. Chiu, and C.-Y. Chen ${ }^{\text {b) }}$ \\ Opto-Electronics and Systems Laboratories, Industrial Technology Research Institute, Hsinchu, Taiwan, \\ Republic of China
}

(Received 8 September 1999; accepted for publication 23 November 1999)

\begin{abstract}
We investigate the photo-oxidation process and the corresponding passivation effects on the optical properties of unintentionally doped $n$-type gallium nitride $(\mathrm{GaN})$. When illuminated with a $253.7 \mathrm{~nm}$ mercury line source, oxidation of $\mathrm{GaN}$ is found to take place in aqueous phosphorus acid solutions with $p \mathrm{H}$ values ranging from 3 to 4 . At room temperature, the photo-oxidation process is found reaction-rate limited and has a peak value of $224 \mathrm{~nm} / \mathrm{h}$ at $p \mathrm{H}=3.5$. Compared with the as-grown $\mathrm{GaN}$ layers, threefold enhancement in the photocurrent and photoluminescence response are observed on the oxidized $\mathrm{GaN}$ surfaces. These results are attributed to the surface passivation effects due to the deep ultraviolet-enhanced wet oxidation on GaN. (C) 2000 American Institute of Physics. [S0003-6951(00)00704-X]
\end{abstract}

The wide band gap III-V nitrides have been long recognized as a material system of outstanding optical, electronic, and thermal properties compared with those of group IV and II-VI materials. Rapid development in the epitaxial growth, doping control, and device processing on group III nitrides has brought in a plethora of research activity ranging from material property investigation ${ }^{1}$ to device application. ${ }^{2}$ The market supply of Nichia's high-luminous indium gallium nitride $(\mathrm{InGaN})$ light emitting diodes, and long lifetime violet InGaN laser diodes represents one such great achievement. ${ }^{3}$ Commercialization of GaN-based ultraviolet (UV) detectors and electronic devices has also recently come into report. ${ }^{4}$ Advantages for such applications include the material's sharp spectral cutoffs that are suitable for solar blind detection, and the wide band gap characteristics that are desirable for high temperature electronics applications. ${ }^{2}$ Although much attention has been emphasized on the device applications, little has been devoted to the issues of GaN surface passivation. Surface passivation by oxidation techniques, in particular, has greatly impacted the design and performance of compound semiconductor devices. ${ }^{5}$ For example, the invention of hydrolyzed wet oxidation on Al-based III-V heterostructures has provided a mechanism in achieving good optical confinement as well as electrical insulation for device application. ${ }^{6}$

An excursion of the above technology to the Ga-based materials has turned out to be a challenge even for a mature system such as gallium arsenide (GaAs). It has been noted the Arrhenius activation energy for hydrolyzed oxidation of aluminum gallium arsenide (AlGaAs) increases dramatically with the Ga composition. ${ }^{7}$ Conventional wisdom has also indicated that direct oxidation of GaAs by the thermal, anodic, and plasma methods inevitably form arsenic-rich oxides that leads to strong surface pinning effects. ${ }^{8}$ One

\footnotetext{
${ }^{a)}$ Electronic mail: peng@cc.ee.ntu.edu.tw

${ }^{b)}$ Now with Epistar Corp., Hsinchu, Taiwan, R. O. C.
}

thus must resort to sophisticated oxidation methods such as in situ deposition of gallium-gadolinium oxide $\left(\mathrm{Ga}_{2} \mathrm{O}_{3}\right)_{1-x}\left(\mathrm{Gd}_{2} \mathrm{O}_{3}\right)_{x}$ at elevated temperature. ${ }^{9}$

Due to the lack of native oxidation techniques on GaN, common practice has pursued the use of silicon oxide $\left(\mathrm{SiO}_{x}\right)$ or silicon nitride $\left(\mathrm{Si}_{x} \mathrm{~N}_{y}\right)$ as the dielectric coating ${ }^{10}$ in the processing of GaN-based emitters ${ }^{11}$ and detectors. ${ }^{12}$ Recent investigation, however, reveals that deposited $\mathrm{SiO}_{2}$ can result in a significant degradation of the photoluminescence (PL) intensity due to the incorporation of oxygen as nonradiative recombination centers in $\mathrm{GaN} .{ }^{13}$ In comparison, deposition of $\mathrm{Si}_{x} \mathrm{~N}_{y}$ has found no improvement on the PL performance of $\mathrm{GaN}$ at all. Gallium oxide, characterized by the low refractive index and high static dielectric constant, has therefore become a promising candidate for resolving the issues of surface passivation on $\mathrm{GaN} .^{1,2}$

To date, there has been little success in the development of native oxidation techniques on III-V nitrides. Anodic oxidation of $\mathrm{GaN}$ in glycol-based electrolyte is one such exception but the oxide thickness depends on the final cell voltage and the $p \mathrm{H}$ value of the electrolyte. ${ }^{14}$ Direct oxidation of $\mathrm{GaN}$ in dry air has also been investigated but reveals a slow oxidation rate of $20 \mathrm{~nm} / \mathrm{h}$ at $900{ }^{\circ} \mathrm{C} .{ }^{15}$ There are, however, concerns regarding the high temperature treatment due to the surface degradation issues. ${ }^{16}$ In this letter we report a use of photochemistry to enable a wet oxidation of $\mathrm{GaN}$ in phosphorus acid $\left(\mathrm{H}_{3} \mathrm{PO}_{4}\right)$ solutions. We thereby are able to reveal a reaction-rate limited oxidation process and observe enhancement in the PL and photocurrent (PC) response on oxidized $\mathrm{GaN}$ for the first time. We attribute the latter to the surface passivation effects affiliated with a good thin film quality of gallium oxide formed on GaN.

The photochemistry process in GaN consists of applying a UV irradiation onto a galvanic cell formed by immersing a $\mathrm{GaN}$ working electrode, a platinum $(\mathrm{Pt})$ counter electrode, and a reference electrode in the electrolyte. ${ }^{17}$ The reaction is that the UV-excited hot carriers at the GaN/electrolyte inter- 


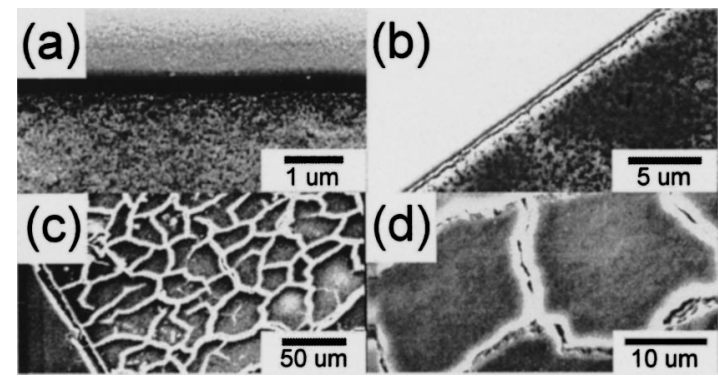

FIG. 1. SEM micrograph of photo-oxidized GaN samples with oxide layer thickness of (a) $100 \mathrm{~nm}$, (b) $450 \mathrm{~nm}$, (c) $1.5 \mu \mathrm{m}$, and (d) magnified picture of (c).

face have excess energy to access the $\mathrm{H}^{+} / \mathrm{H}_{2}$ and $\mathrm{OH}^{-} / \mathrm{O}_{2}$ redox levels in water and enhance the oxidative dissolution of GaN. ${ }^{18}$ Our experimental setup consisted of a galvanic cell illuminated by a $253.7 \mathrm{~nm}$ mercury $(\mathrm{Hg})$ line source of $10 \mathrm{~mW} / \mathrm{cm}^{2}$ intensity. The metal-organic chemical vapor deposition (MOCVD) grown unintentionally doped $4-\mu \mathrm{m}-$ thick GaN films were measured to be $n$ type and had a carrier concentration of $\sim 10^{17} \mathrm{~cm}^{-3} .{ }^{19}$ A bilayer Ti/Pt metal mask was electron-beam evaporated and served as the cathode in the galvanic cell. The experiments were carried out at room temperature with no bias applied between the GaN sample and the Pt counter electrode. The oxidized samples were dehydrated at $150{ }^{\circ} \mathrm{C}$ for $3 \mathrm{~h}$ before loading into a Philips XL30 scanning electron microscope (SEM) to examine the surface morphology.

Shown in Fig. 1 are the SEM micrographs of the photooxidized GaN samples with oxide thickness of (a) $100 \mathrm{~nm}$, (b) $450 \mathrm{~nm}$, and (c) $1.5 \mu \mathrm{m}$, respectively. Here the $\mathrm{GaN}$ samples were photo-oxidized in a $\mathrm{H}_{3} \mathrm{PO}_{4}$ electrolyte of $p \mathrm{H}$ $=3.5$. We note the thin oxidized $\mathrm{GaN}$ sample A has a purplebluish color and reveals fine grain crystallites in Fig. 1(a). In comparison, the magnified SEM micrograph of Fig. 1(d) of the $1.5 \mu \mathrm{m}$ oxidized $\mathrm{GaN}$ sample $\mathrm{C}$ reveals microcracks associated with thick oxide growth. They are typically agglomerated into a disk-like shape with a lateral size of $20 \mu \mathrm{m}$. The transition from a transparent-looking, mirror-like oxidized surface of Fig. 1(b) into a peeling appearance of Fig. 1(c) indicates a process of stress development along the oxide/ $\mathrm{GaN}$ interface. The excess strain energy is then accommodated by the formation of microcracks with the thick oxide peeling at the cracks. ${ }^{20}$

A quantitative composition analysis is proceeded with a EDAX DX4 energy-dispersive $\mathrm{x}$-ray spectrometer (EDX). Shown in Fig. 2 are the EDX data of the oxidized GaN sample B with a 450-nm-thick oxide and spotted from the

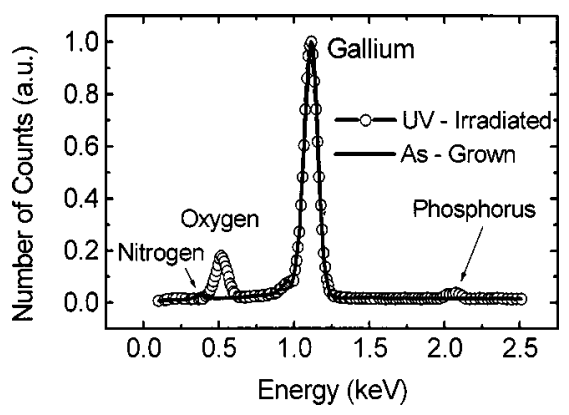

FIG. 2. EDX analysis of the as-grown and photo-oxidized GaN sample B.

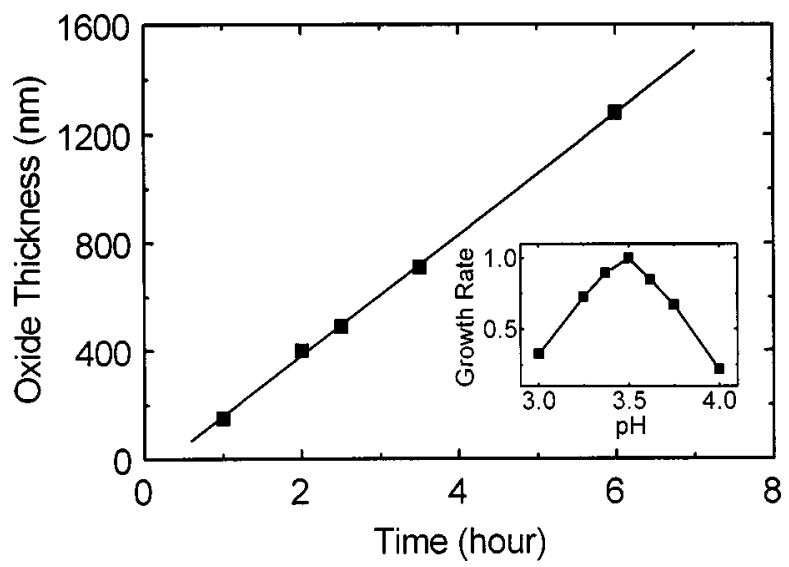

FIG. 3. Time dependence of the photogrown oxide at $p \mathrm{H}=3.5$. Inset shows the $p \mathrm{H}$ dependence of the normalized photo-oxidation rate in aqueous $\mathrm{H}_{3} \mathrm{PO}_{4}$ solutions.

UV-illuminated and the as-grown area, respectively. The normalized element analysis indicates an atomic ratio (At. \%) of $\mathrm{O}: \mathrm{Ga}: \mathrm{P}=58.85 \%: 40.23 \%: 0.92 \%$ from the oxidized area. The presence of a weak phosphorus signal suggests a formation of phosphate precursor layer at the oxide/ $\mathrm{GaN}$ interface, as is the case in the anodic oxidation process using phosphate solutions. ${ }^{21}$ Moreover, the 2:3 atomic ratio of $\mathrm{Ga}$ to $\mathrm{O}$ indicates that the chemical composition of the dehydrated oxide is likely to be $\mathrm{Ga}_{2} \mathrm{O}_{3}$. This is supported by a subsequent dissolution of the oxide layer in a $2 \mathrm{M}$ potassium hydroxide $(\mathrm{KOH})$ solution. Had gallium hydroxide formed in the oxidation process, it would be insoluble in the alkaline solutions. ${ }^{22}$

Illustrated in Fig. 3 is the time dependence of the photogrown oxide in a $\mathrm{H}_{3} \mathrm{PO}_{4}$ electrolyte of $p \mathrm{H}=3.5$. Data shown in Fig. 3 exhibits a linear time dependence and the slope reveals a reaction rate of $224 \mathrm{~nm} / \mathrm{h}$. The former indicates that a reaction-rate limited process has taken place. We also note the UV-assisted wet oxidation rate of $\mathrm{GaN}$ at room temperature is one order of magnitude higher than previously reported in the high temperature treatment. ${ }^{15}$ These observations suggest the UV-excited hot-carrier injection at the GaN/electrolyte interface can rapidly access the redox levels in water to initiate an efficient oxidation process. Also shown in Fig. 3 is the $p \mathrm{H}$ dependence of the normalized UVassisted oxidation rate of $\mathrm{GaN}$ in aqueous $\mathrm{H}_{3} \mathrm{PO}_{4}$ solutions. The observation of a peak oxidation rate indicates a hydration action such that both of the solute $\left(\mathrm{H}_{3} \mathrm{PO}_{4}\right)$ and the solvent (free water molecules) play an important role in the photo-oxidation process. ${ }^{23}$

The spectral photocurrent (PC) response of the oxidized and as-grown $\mathrm{GaN}$ sample $\mathrm{A}$ were measured in a metalsemiconductor-metal (MSM) configuration using the Ti/Pt bilayer as the metal contact. For the PC measurement, a xenon $(\mathrm{Xe})$ lamp and a standard lockin technique were used. The chopper frequency was typically set at $550 \mathrm{~Hz}$ with a 1.5 $\mathrm{V}$ bias applied between the electrodes. The room temperature excitonic PC response shown in Fig. 4 from the as-grown sample indicates a good quality thin film of GaN. In comparison, data for the thin oxidized sample A covered with a 100-nm-thick gallium oxide reveal a threefold increase in the PC response. We note that such an optical enhancement spans a spectral range from 365 to $250 \mathrm{~nm}$ and has a rela- 


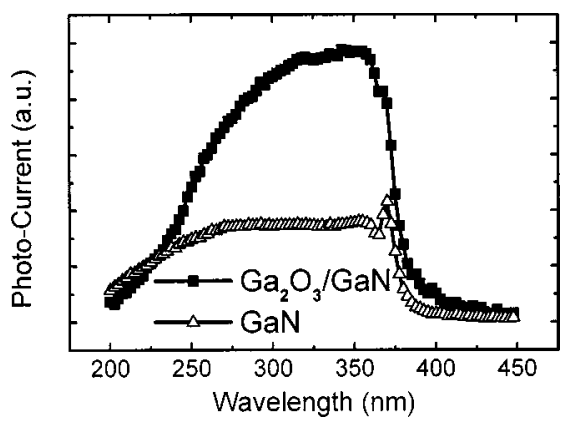

FIG. 4. The PC response from the as-grown and photo-oxidized GaN sample A.

tively flat spectral response. Photoluminescence (PL) experiments were also taken on the same set of samples using a 20 $\mathrm{mW}$, Liconix $325 \mathrm{~nm}$ helium-cadmium $(\mathrm{He}-\mathrm{Cd})$ laser equipped with a grating spectrometer and a Hamamatsu R943-92 GaAs photomultiplier tube. A close examination of Fig. 5 also reveals a similar optical enhancement in the bandedge emission spectrum. Since the Fresnel loss due to the optical reflection at the GaN/air interface is no more than $20 \%$, the threefold enhancement in the PC and PL optical response on the oxidized GaN samples are ascribed to an efficient surface passivation effect. Unlike the gradual degradation of PL intensity previously reported in the waterflown oxidation technique, ${ }^{24}$ the persistent enhancement of the PC and PL response from the UV-assisted oxidation process represents a reliable passivation method that will be valuable to the application of nitride-based opto-electronic devices.

In summary, we report a UV-enhanced, reaction-rate limited wet oxidation process on $\mathrm{GaN}$ at room temperature. A peak oxidation rate as high as $224 \mathrm{~nm} / \mathrm{h}$ can be achieved in

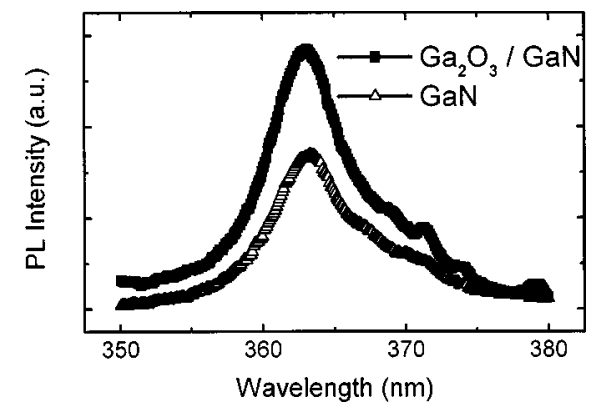

FIG. 5. The PL response from the as-grown and photo-oxidized GaN sample A. aqueous $\mathrm{H}_{3} \mathrm{PO}_{4}$ solution at $p \mathrm{H}=3.5$. Enhancement in the $\mathrm{PC}$ and PL response from the oxidized GaN surfaces suggest an efficient surface passivation effect due to the photo-oxidation process on $\mathrm{GaN}$.

The authors acknowledge discussion with Dr. C.-A. Chang at ITRI and Professor G.-J. Jan at NTU. This research was supported by the National Science Council, Grant No. 89-2215-E-002-023 and by the R. O. C. Department of Economy under Contract No. 89S33-T1.

${ }^{1}$ O. Ambacher, J. Phys. D: Appl. Phys. 31, 2653 (1998).

${ }^{2}$ S. J. Pearton, J. C. Zolper, R. J. Shul, and F. Ren, J. Appl. Phys. 86, 1 (1999).

${ }^{3}$ S. Nakamura, Semicond. Sci. Technol. 14, R27 (1999).

${ }^{4}$ Nitride news in Compound Semiconductor winter II issue, 1998 (unpublished), p. 10.

${ }^{5} \mathrm{C}$. W. Wilmsen, Physics and Chemistry of III-V Compound Semiconductor Interface (Plenum, New York, 1985), p. 403.

${ }^{6}$ A. R. Sugg, N. Holonyak, Jr., J. E. Baker, F. A. Kish, and J. M. Dallesasse, Appl. Phys. Lett. 58, 1199 (1991).

${ }^{7}$ K. D. Choquette, K. M. Geib, C. I. H. Ashby, R. D. Twesten, O. Blum, H. Q. Hou, D. M. Follstaedt, B. E. Hammons, D. Mathes, and R. Hull, IEEE J. Sel. Top. Quantum Electron. 3, 916 (1997).

${ }^{8}$ C. M. Finnie and P. W. Bohn, Appl. Phys. Lett. 74, 1096 (1999).

${ }^{9}$ J. Kwo, D. W. Murphy, M. Hong, R. L. Opila, J. P. Mannaerts, A. M. Sergent, and R. L. Masaitis, Appl. Phys. Lett. 75, 1116 (1999).

${ }^{10} \mathrm{~S}$. Arulkumaran, T. Egawa, H. Ishikawa, T. Jimbo, and M. Umeno, Appl. Phys. Lett. 73, 809 (1998).

${ }^{11}$ S. Nakamura, M. Senoh, S. I. Nagahama, N. Iwasa, T. Yamada, T. Matsushita, H. Kiyoku, Y. Sugimoto, T. Kozaki, H. Umemoto, M. Sano, and K. Chocho, Appl. Phys. Lett. 72, 2014 (1998).

${ }^{12}$ J. C. Carrano, P. A. Grudowski, C. J. Eiting, R. D. Dupuis, and J. C. Campbell, Appl. Phys. Lett. 70, 1992 (1997).

${ }^{13}$ X. C. Wang, S. J. Xu, S. J. Chua, K. Li, X. H. Zhang, Z. H. Zhang, K. B. Chong, and X. Zhang, Appl. Phys. Lett. 74, 818 (1999).

${ }^{14}$ T. Tomoyasu, H. Sato, M. Hao, M. Nozaki, Y. Naoi, and S. Sakai, in Second International Conference on Nitride Semiconductors, ICNS'97, paper P2-25 (unpublished).

${ }^{15}$ S. D. Wolter, B. P. Luther, D. L. Waltemyer, C. Önneby, S. E. Mohney, and R. J. Molnar, Appl. Phys. Lett. 70, 2156 (1997).

${ }^{16}$ C. B. Vartuli, S. J. Pearton, C. R. Abernathy, J. D. MacKenzie, E. S. Lambers, and J. C. Zolper, J. Vac. Sci. Technol. B 14, 3523 (1996).

${ }^{17}$ M. S. Minsky, M. White, and E. L. Hu, Appl. Phys. Lett. 68, 1531 (1996).

${ }^{18}$ L.-H. Peng, C.-W. Chuang, J.-K. Ho, C.-N. Huang, and C.-Y. Chen, Appl. Phys. Lett. 72, 939 (1998).

${ }^{19}$ C. F. Lin, G. C. Chi, M. S. Feng, J. D. Kuo, J. S. Tsang, and J. M. Huang, Appl. Phys. Lett. 68, 3758 (1996).

${ }^{20}$ J. M. Dallesasse, N. El-Zein, N. Holonyak, K. C. Hsieh, R. D. Burnham, and R. D. Dupuis, J. Appl. Phys. 68, 2235 (1990).

${ }^{21}$ P. Schmuki, G. I. Sproule, J. A. Bardwell, Z. H. Lu, and M. J. Graham, J. Appl. Phys. 79, 7303 (1996).

${ }^{22}$ J. I. Pankove, J. Electrochem. Soc. 119, 1118 (1972).

${ }^{23}$ L.-H. Peng, C.-W. Chuang, Y.-C. Hsu, J.-K. Ho, C.-N. Huang, and C.-Y. Chen, IEEE J. Sel. Top. Quantum Electron. 4, 564 (1998).

${ }^{24}$ S. D. Offsey, J. M. Woodall, A. C. Warren, P. D. Kirchner, T. I. Chappell, and G. D. Pettit, Appl. Phys. Lett. 48, 475 (1986). 